\title{
Influência do tempo e da temperatura de armazenamento nos resultados do processamento de amostras de sangue de bovinos
}

Felipe Eduardo Dal Mas;, Matheus Morillo Bär, Luana Gomes Fernandes, Maria Victória Ferreira Barreiros, Lindomar Fernandes Pessoa, Marla Schneider, Leiluana Camila Rettig, Pedro Argel Zadinelo Moreira, Marilene Machado Silva, Erica Cristina Bueno do Prado Guirro

Universidade Federal do Paraná (UFPR), Curitiba, PR, Brasil

*Autor correspondente

e-mail: dalmasfelipe@gmail.com

\section{Resumo}

O uso de exames laboratoriais é uma alternativa de grande valor para o médico veterinário, porém a campo, onde grande parte dos atendimentos clínicos de bovinos ocorrem, estes exames são de difícil realização, sendo necessária a coleta e transporte da amostra de sangue, destinando-a a um laboratório de análises clínicas. Desta maneira, é fundamental determinar por quanto tempo estas amostras permanecem viáveis e de que maneira devem ser armazenadas, para que continuem fornecendo um resultado correto, fidedigno, o qual é o objetivo do presente trabalho. Para realização deste experimento, foi coletado sangue venoso de oito bovinos, $112 \mathrm{ml}$ de cada animal, distribuídos em 14 tubos secos e 14 com fluoreto de sódio, sendo sete de cada um desses tubos mantidos sob refrigeração $\left(4^{\circ} \mathrm{C}\right)$ ou em temperatura ambiente $\left(22^{\circ} \mathrm{C}\right)$. Com estas amostras foram realizados exames bioquímicos em T0 (imediato após a coleta) e após 2 (T2), 4 (T4), 8 (T8), 12 (T12), 24 (T24) e 48 horas (T48). A análise dos dados foi baseada nas médias obtidas em cada tempo, sendo interrompido o processamento das amostras quando os resultados de determinado tempo diferiram mais que 6\% (acima ou abaixo) dos valores obtidos em T0. Desta maneira, ao interromper o exame, já determinou-se o tempo limite para realização do mesmo. 0 tempo máximo de cada variável sob refrigeração e temperatura ambiente foi, respectivamente: aspartato aminotransferase e creatina quinase T4h e T4h; gama-glutamil transferase T4h e T8h; ureia e creatinina T2h e T2h; proteínas totais T48h e T48h; albumina T48h e T8h; lactato T0 e T0; glicose T48h e T4h. Sendo assim, podemos concluir que as amostras permitem, em condições de armazenamento adequadas para cada exame, um determinado tempo de armazenamento, variável, mas que possibilita o processamento horas após a coleta da amostra para a maioria dos exames realizados. 